\title{
Influência da dureza e potencial hidrogeniônico da calda de pulverização sobre o controle do ácaro-da-leprose em frutos de laranja doce
}

\author{
Evandro Pereira Prado ("); Demétrius de Araújo; Carlos Gilberto Raetano; \\ Mário Henrique Ferreira do Amaral Dal Pogetto; Hélio Oliveira Aguiar-Júnior; \\ Rafael de Souza Christovam
}

Universidade Estadual Paulista "Julio de Mesquita Filho" (UNESP), Faculdade de Ciências Agronômicas (FCA), Caixa Postal 237. 18610-307 Botucatu (SP).

(*) Autor correspondente: epprado@hotmail.com

Recebido: 25/mai./2009; Aceito: 28/fev./2011.

\begin{abstract}
Resumo
Muitos são os relatos de ineficiência de agrotóxicos no controle de pragas quando estes são preparados em soluções com água dura e pH elevado. Assim, o trabalho teve como objetivo avaliar o efeito da dureza da água e o pH de soluções acaricidas, em diferentes períodos de tempo após o preparo da calda (0 e 24 horas) no controle do ácaro-da-leprose Brevipalpus phoenicis (Geijskes). O bioensaio foi conduzido sobre frutos de Citrus sinensis (L.) Osbeck cv. Valência. Utilizou-se o delineamento inteiramente ao acaso, com 14 tratamentos e 4 repetições, sendo a parcela experimental composta de um fruto com 10 fêmeas do acarino por fruto. Os acaricidas testados nas dosagens registradas foram: propargite, hexitiazoxi e espirodiclofeno. A pulverização dos frutos foi feita em torre de Potter adaptada, conferindo um volume equivalente a 1616 $\mathrm{L} \mathrm{ha}^{-1}$. As avaliações foram realizadas até 49 dias após aplicação dos produtos, contando o número de adultos, ninfas e, na avaliação final, o número de ovos do acarino por fruto. A dureza da água, pH e tempo de preparo não interferiram no controle do ácaro da leprose. Os acaricidas, após mistura com os diferentes tipos de água, não alteraram o pH das soluções, os quais mostraram pequenas variações de $\mathrm{pH}$ no decorrer de 24 horas. Todos os acaricidas propiciaram alta eficácia de controle do acarino nas diferentes condições de preparo de calda, mostrando que esses fatores não interferiram no potencial acaricida.

Palavras-chave: Controle químico, qualidade da água de pulverização, ácaro-da-leprose, citros.
\end{abstract}

\section{Effects of water hardness and $\mathrm{pH}$ in acaricide spray solutions on the control of Brevipalpus phoenicis on sweet orange fruit}

\section{Abstract}

There are many reports of inefficiency by pesticides in the pest control when they are prepared in solutions with water hardness and high $\mathrm{pH}$. Therefore, the research aimed to evaluate the effects of water hardness, $\mathrm{pH}$ and time after preparation (0 and 24h) of acaricides spray solutions on control of the citrus leprosis mite, Brevipalpus phoenicis (Geijskes). The bioassay was carried out on fruit of Citrus sinensis (L.) Osbeck cv. Valência. A completely randomized design with fourteen treatments and four repetitions was used. The sample unit was composed by one fruit with ten mite females. The following acaricides were tested: propargite, hexythiazox and spirodiclofen. The spray on fruit was done by modified Potter tower adjusted to an equivalent volume of $1616 \mathrm{~L} \mathrm{ha}^{-1}$. The evaluations were done until 49 days after the acaricide application by counting the number of adults, nymphs and the number of eggs in the last evaluation. Water hardness, hydrogenionic potential and time after preparation of spray solution did not interfere on leprosis mite control. After the mixture with different water types, the acaricides did not modify the $\mathrm{pH}$ of the spray solutions, which showed low variations in pH values over 24 h. All acaricides showed an efficient control of leprosis mite, regardless of the variations in water hardness and $\mathrm{pH}$.

Key words: Chemical control, spray water quality, leprosis mite, citrus. 


\section{INTRODUÇÃO}

O ácaro-da-leprose Brevipalpus phoenicis (Geijskes) (Acari: Tenuipalpidae) é uma das principais pragas da cultura dos citros, por ser o vetor do virus (Citrus leprosis virus CiLV) que causa a doença leprose dos citros (Musumeci e Rossetti, 1963; Kitajima et al., 1972; Chiavegato et al., 1982). Os principais sintomas da doença leprose dos citros são manchas em frutos, folhas e ramos, provocando queda prematura de frutos, seca de ramos, e levando a planta ao definhamento (Rodrigues et al., 2001). A incidência severa da moléstia pode tornar um pomar economicamente inviável, dada a baixa produtividade e redução no tamanho dos frutos, embora não afete a qualidade do suco (CHiavegato et al., 1982; Rodrigues e Oliveira, 2005).

O principal método de controle do ácaro-da-leprose consiste através de pulverizaçóes com soluçôes acaricidas. Para que haja sucesso no controle do vetor é necessário realizar pulverizaçóes em que a cobertura da planta com a solução acaricida seja a mais uniforme possível, pois o ácaro possui tamanho reduzido, corpo plano e pelo comportamento de se alojar nas partes internas das copas das plantas.

Quanto à tecnologia de aplicação, RAmos et al. (2004) afirmam que diferentes produtos fitossanitários, formulações, manejo de produtos e técnicas de pulverização, em geral com volumes altos, são utilizados para o controle de B. phoenicis.

Além do volume de pulverizaçáo, outros fatores como a presença de substâncias dissolvidas na água (gases, líquidos ou sólidos), bem como outras impurezas, que podem variar em função da fonte de água e local de coleta, podem ou náo afetar a açáo de um produto fitossanitário, quando utilizada como diluente para o preparo da calda de pulverização. Assim, a qualidade química da água em relação ao potencial hidrogeniônico $(\mathrm{pH})$, sais e íons dissolvidos, é um fator a ser considerado no tratamento fitossanitário. No que refere à qualidade da água, a "dureza", definida como a concentração de íons alcalino-terrosos presentes na água, expressa na forma de $\mathrm{CaCO}_{3}$ (ppm), representados geralmente pelos íons $\mathrm{Ca}^{+2}$ e $\mathrm{Mg}^{+2}$ originados de carbonatos, bicarbonatos, cloretos e sulfatos, é uma propriedade capaz de interferir negativamente nas caldas de produtos fitossanitários. Volumes maiores de água agravam o problema da dureza, pois haverá maior quantidade de cátions acompanhando essa água, para interferir com o produto fitossanitário ou com os adjuvantes na calda de pulverização (Kissmann, 1997). Essa situação pode se tornar um agravante quando volumes elevados sáo utilizados em pulverizaçôes para o controle do ácaro-da-leprose em citros.

$\mathrm{O}$ pH da água pode interferir na ação de um ingrediente ativo, pois altas concentraçôes de íons $\mathrm{H}^{+}$ou $\mathrm{OH}^{-}$ poderão reagir com o ingrediente ativo, diminuindo, assim, a concentração deste na calda (ConCeição, 2003). O acréscimo de produtos fitossanitários à água tende a alterar os valores de $\mathrm{pH}$ da calda de pulverização. Esses valores de $\mathrm{pH}$ influenciam na eficiência dos produtos utilizados, além de interferir nos níveis de dissociação dos ingredientes ativos e na estabilidade física das soluçóes (Kissmann, 1998). Reeves (1983), estudando a ação do $\mathrm{pH}$ sobre a estabilidade dos produtos fitossanitários, observou que águas com altos níveis de $\mathrm{pH}$ podem provocar hidrólise alcalina dos produtos, e que a perda provocada pela hidrólise é irreversível, levando a uma ineficiência do produto.

Ao avaliar a estabilidade química do inseticida piretróide cipermetrina em águas com diferentes valores de pH, Al-Mughrabi e Nazer (1991) constataram que houve maior porcentagem de hidrólise da molécula inseticida $(31,2 \%)$ quando em mistura com a fonte de água de $\mathrm{pH}$ mais elevado ( $\mathrm{pH} 8,38), 24$ horas após o preparo da calda. Para a mesma calda, 20 horas antes, a perda foi de $20 \%$. Deve-se salientar que os autores não realizaram teste de eficácia para verificar se essa taxa de degradação seria suficiente para reduzir significativamente a capacidade de controlar um inseto-alvo.

Com base na pesquisa de Al-Mughrabi e Nazer (1991), pode-se supor que o tempo de preparo da calda até a sua utilização é outro fator que pode interferir na eficácia do produto fitossanitário. Principalmente nas grandes propriedades, é comum realizar o preparo das caldas de pulverização com considerável antecedência, até mesmo de um dia, a fim de melhorar a operacionalização do sistema, levando menos tempo para se pulverizar toda a área plantada. No entanto, a presença de condiçóes climáticas adversas pós-preparo da calda, pode fazer com que esta continue por longo período armazenada no próprio tanque do pulverizador, onde os produtos permanecerão mais tempo reagindo com o diluente (água) e outros componentes.

Fica evidente que a influência negativa do $\mathrm{pH}$ da água em caldas para pulverizaçôes é bastante controversa. ANDRADE (1997) constatou que os acaricidas hexitiazoxi, óxido de fenbutatina e dicofol não foram influenciados pelo $\mathrm{pH}$ da calda $(3,6$ e 9) quanto às suas ações acaricidas sobre $B$. phoenicis.

Considerando a escassez e divergência de estudos referentes à eficácia de produtos fitossanitários em caldas com o uso de diferentes fontes de água e, consequentemente, diferentes níveis de $\mathrm{pH}$ e "dureza", bem como, do tempo de armazenamento das caldas até sua utilização, o presente trabalho objetivou estudar a interferência desses fatores sobre a eficácia de três acaricidas no controle de $B$. phoenicis sobre frutos cítricos.

\section{MATERIAL E MÉTODOS}

\section{Criação de B. phoenicis}

A criação de manutenção do ácaro $B$. phoenicis foi realizada em laboratório, utilizando-se frutos de laranja doce 
da variedade Valência [Citrus sinensis (L.) Osbeck], que é favorável ao desenvolvimento desse ácaro (CHIAvEgATO e Mischan, 1987). Os frutos colhidos de um pomar onde náo ocorreu nenhum tipo de controle químico foram lavados em água corrente, deixados para secar, e posteriormente parafinados, deixando-se uma arena sem parafina de $14 \mathrm{~cm}^{2}$ a $16 \mathrm{~cm}^{2}$ na região estilar do fruto (oposta ao pedúnculo) para a colonização do ácaro. A arena foi circundada por cola Tanglefoot ${ }^{\circledR}$ para o confinamento dos ácaros. Foram transferidos 20 a 30 ácaros por fruto com o auxílio de pincel com apenas um pelo e microscópio estereoscópio. Os frutos foram mantidos e acondicionados em uma prancha de isopor com 18 orifícios. A criação foi mantida em ambiente climatizado $\left(25 \pm 2^{\circ} \mathrm{C}, 70 \pm 10 \%\right.$ de U.R. e 14 horas de fotofase $)$ e os frutos foram renovados a cada 40 a 60 dias, conforme a sanidade deles.

\section{Preparo dos frutos para o experimento}

Foi utilizado o mesmo procedimento adotado para a manutenção da criação do acarino nos frutos, acrescido de uma limpeza da arena com pincel n. ${ }^{\circ} 2$ para retirada de possíveis ácaros predadores. Após a limpeza, fez-se com um pincel fino quatro listras de gesso paralelas na arena (Figura 1), visando simular rugas semelhantes a lesóes da doença fúngica verrugose pois, conforme afirmaçóes de Albuquerque et al. (1997), a fêmea realiza a postura, isoladamente, em locais protegidos, principalmente nos frutos cítricos com lesóes de verrugose. Posteriormente as arenas foram circundadas com cola (Tanglefoot ${ }^{\circ}$ ) para que as fêmeas do ácaro, a serem transferidas, ficassem confinadas.

Depois de preparados, foram transferidas para cada fruto 10 fêmeas adultas de $B$. phoenicis com auxílio de um pincel de apenas um único pelo, sob microscópio estereoscópio. Quatro dias após a infestação efetuou-se nova contagem do número de fêmeas e do número de ovos por arena, constituindo assim a avaliação prévia.

\section{Delineamento experimental e tratamentos}

O delineamento experimental foi inteiramente ao acaso com 14 tratamentos e quatro repetiçóes, distribuídos em esquema fatorial $(3 \times 2 \times 2)+2$ testemunhas. Foram avaliados três acaricidas disponíveis comercialmente no Brasil, contendo os seguintes ingredientes ativos: hexitiazoxi, propargite, espirodiclofeno; duas fontes de água: a primeira água tratada (do sistema público municipal de abastecimento do município de Botucatu, SP), com valor médio de $\mathrm{pH}$ igual a 7,7; e a segunda proveniente de poço artesiano do município de Pereiras (SP), sendo considerada água "dura", com alcalinidade total de $438 \mathrm{mg}$ de

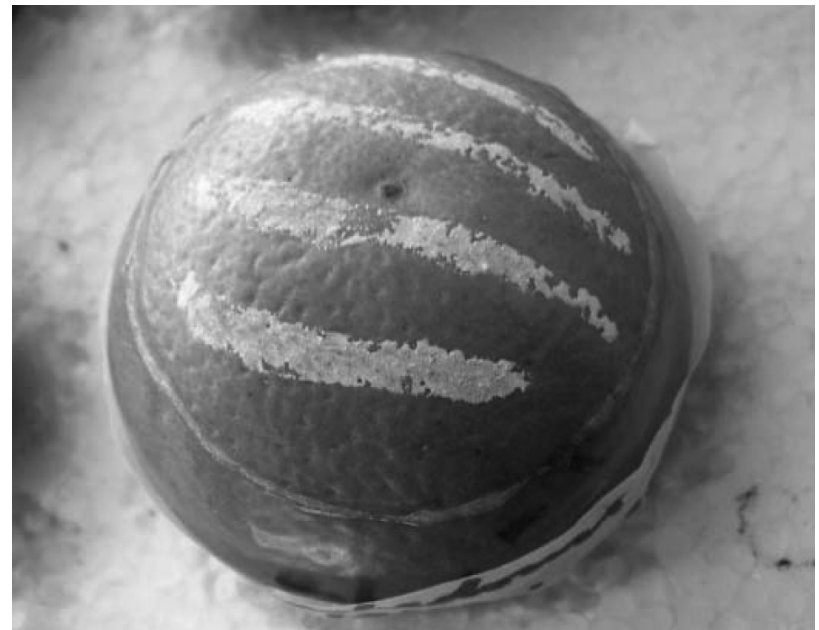

Figura 1. Fruto de laranja Valência preparado para transferência dos ácaros.

$\mathrm{CaCO}_{3} \mathrm{~L}^{-1}$ e pH médio igual a 9,32; e dois tempos de aplicação - logo após preparo da calda (acaricida + água) e 24 horas após o preparo da calda. Para o controle da influência dos fatores, mantiveram-se dois tratamentos testemunha: pulverização somente com água tratada ou com água dura. Os três acaricidas foram empregados nas dosagens recomendadas e registradas no Ministério da Agricultura, Pecuária e Abastecimento, segundo Andrei (2005), para o controle do ácaro-da-leprose B. phoenicis (Tabela 1). Dessa forma, com os fatores avaliados, foram constituídos os tratamentos descritos na tabela 2.

\section{Aplicação dos produtos}

Quatro dias após a infestação dos frutos, os acaricidas foram aplicados, utilizando torre de Potter adaptada com $464 \mathrm{~cm}^{2}$ de área aplicável, com volume de calda de $9 \mathrm{~mL}$ na pressão de $34 \mathrm{kPa}$, equivalente a um volume de calda de aproximadamente $1616 \mathrm{~L} \mathrm{ha}^{-1}$. No momento da aplicação, as condições climáticas eram de: temperatura de $24 \pm 1^{\circ} \mathrm{C}$ e $51 \pm 5 \%$ de umidade relativa do ar. Após cada tratamento, a torre foi lavada com água destilada para descontaminação do tratamento anterior. Depois da aplicação, os frutos foram mantidos em laboratório na mesma condição ambiente.

\section{Avaliações}

Foram realizadas avaliaçôes do número de fêmeas dos ácaros vivos com 0, (avaliação prévia) 3, 6, 17 e 49 dias após a aplicação e de ninfas aos 12, 22 e 49 dias após a aplicação, com auxílio de um microscópio estereoscópio. Foram considerados mortos os ácaros fitófagos adultos e ninfas que não conseguiam se locomover por uma distância mí- 
Tabela 1. Acaricidas e dosagens avaliadas no controle do ácaro da leprose $B$. phoenicis, em água com diferentes níveis de dureza e pH

\begin{tabular}{|c|c|c|c|c|c|}
\hline \multirow{2}{*}{ Produto Técnico } & \multirow{2}{*}{$\begin{array}{l}\text { Formulaçãa/ } \\
\text { Concentração (1) }\end{array}$} & Dosagem & Dosagem & \multirow{2}{*}{ Classe toxicológica } & \multirow{2}{*}{ Grupo químico } \\
\hline & & p.c. $100 \mathrm{~L}$ & (g 100 L i.a.) & & \\
\hline Propargite & CE 720 & $100 \mathrm{~mL}$ & 72 & II & sulfito de alquila \\
\hline Hexitiazoxi & PM 500 & $3 \mathrm{~g}$ & 1,5 & III & tiazolidinacarboxamida \\
\hline Espirodiclofeno & SC 240 & $25 \mathrm{~mL}$ & 6,0 & III & cetoenol \\
\hline
\end{tabular}

(') g.i.a. $\mathrm{kg}^{-1}$ ou g.i.a. $\mathrm{L}^{-1}$ de p.c.: Produto comercial; i.a.: ingrediente ativo; $\mathrm{CE}=$ Concentrado Emulsionável; PM= Pó Molhável; SC= Suspensão Concentrada.

Tabela 2. Características das caldas de pulverização avaliadas no controle de Brevipalpus phoenicis sobre frutos de laranja doce

\begin{tabular}{|c|c|c|c|}
\hline \multirow{2}{*}{ Tratamentos } & \multicolumn{3}{|c|}{ Fatores } \\
\hline & Acaricidas & Fonte de água & Tempo após preparo da calda \\
\hline T1 & \multirow{4}{*}{ propargite } & Água dura & Tempo zero \\
\hline T2 & & Água tratada & Tempo zero \\
\hline T3 & & Água dura & 24 horas \\
\hline T4 & & Água tratada & 24 horas \\
\hline T5 & \multirow{4}{*}{ hexitiazoxi } & Água dura & Tempo zero \\
\hline T6 & & Água tratada & Tempo zero \\
\hline T7 & & Água dura & 24 horas \\
\hline T8 & & Água tratada & 24 horas \\
\hline T9 & \multirow{4}{*}{ espirodiclofeno } & Água dura & Tempo zero \\
\hline T10 & & Água tratada & Tempo zero \\
\hline T11 & & Água dura & 24 horas \\
\hline $\mathrm{T} 12$ & & Água tratada & 24 horas \\
\hline T13 & Testemunha & Água dura & Tempo zero \\
\hline T14 & Testemunha & Água tratada & Tempo zero \\
\hline
\end{tabular}

nima equivalente ao comprimento do seu corpo ao serem tocados com um pincel de pelo macio.

$\mathrm{O}$ acompanhamento do $\mathrm{pH}$ da calda de pulverizaçáo para cada um dos 14 tratamentos, com três repetiçóes, foi realizado com auxílio de medidor de $\mathrm{pH}$ portátil, ao longo de diferentes períodos após preparo da calda: no momento da mistura (tempo zero), 1, 2, 4, 8 e 24 horas após.

\section{Análise estatística}

Os dados relativos à mortalidade de B. phoenicis foram transformados em raiz de $\mathrm{x}$ e submetidos à análise de variância, pelo teste F, no esquema fatorial (três acaricidas, duas fontes de água, dois tempos de aplicação), e as médias comparadas pelo teste de Tukey a 5\% de probabilidade. Para as análises estatísticas relativas aos dados de mortalidade dos adultos e ninfas dos ácaros, foi utilizado o programa computacional ASSISTAT (Silva e Azevedo, 2006). Os percentuais de eficiência foram calculados segundo a fórmula de Аввотт (1925) descrita em NaKano et al. (1981). Para o cálculo de eficiência dos acaricidas foram realizadas comparaçóes com os respectivos tratamentos-testemunha; onde se aplicou água "dura", comparou-se aos tratamentos em que a calda acaricida foi preparada com essa fonte de água e o mesmo procedimento adotado para os tratamentos que utilizaram a água tratada. Foram elaborados gráficos através do programa computacional Excel para Windows ${ }^{\circledast}$ com os dados de $\mathrm{pH}$.

\section{RESULTADOS E DISCUSSÃO}

As interaçôes entre os fatores tipos de água (água dura e tratada), tempos de preparo (0 e 24 horas), e acaricidas (propargite, hexitiazoxi e espirodiclofeno) não foram significativos e, dessa forma, pode-se inferir que os fatores agem de forma independente no controle de B. phoenicis (Tabela 3).

Aos três dias após aplicação (DAA) os tratamentos com propargite (tratamentos 1 a 4) nos diferentes tipos de caldas de pulverização proporcionaram bom controle do ácaro, com alta mortalidade e médias de sobrevivência, se não igual, próximas de zero (Tabela 4). O tempo de preparo e o tipo de água utilizados não influenciaram a eficácia do produto no controle do acarino, não havendo diferença significativa entre tratamentos. Aos 6 DAA, todos os tratamentos com propargite tiveram 100\% de eficiência no controle desse acarino. Oliveira et al. (1997; 2003), estudando o controle químico do ácaro-da-leprose 
em condiçóes de campo, obtiveram resultados semelhantes com o acaricida propargite $\left(100 \mathrm{~mL}\right.$ do p.c. $\left.100 \mathrm{~L}^{-1}\right)$ aos 7 e 9 DAA respectivamente.

Nos tratamentos à base de hexitiazoxi (Tratamentos 5 a 8), como era esperado, não houve bom controle dos adultos do ácaro nas avaliaçóes realizadas até 17 DAA, não diferindo significativamente dos tratamentos onde não foram aplicados acaricidas (tratamentos 13 e 14) (Tabela 4). Somente aos $49 \mathrm{DAA}$, apesar de observadas diferenças significativas no número de ácaros, em comparação aos demais produtos químicos, a porcentagem de controle foi superior a $92 \%$. A eficiência do produto foi constatada tardiamente, pelo fato de este acaricida possuir ação específica sobre ovos e larvas. Assim, o efeito na redução da população de adultos é observado quando os primeiros completam seu ciclo de vida e não mais existem ácaros jovens devido à morte e esterilização, respectivamente, das larvas e ovos existentes. ANDrade (1997), estudando o efeito de hexitiazoxi aplicados em diferentes níveis de $\mathrm{pH}$ e imediatamente ou a 4 horas após a preparação da calda, também não observou diferenças de controle quando avaliou a sobrevivência de adultos do ácaro da leprose, em

Tabela 3. Análise de variância e coeficiente de variação dos dados relativos ao número de adultos, ninfas e ovos do ácaro da leprose

\begin{tabular}{|c|c|c|c|c|c|c|c|c|}
\hline \multirow{2}{*}{ Fatores de variação } & \multirow{2}{*}{$\begin{array}{l}\text { Graus de } \\
\text { liberdade }\end{array}$} & \multicolumn{4}{|c|}{ Valores de F (adultos) } & \multicolumn{3}{|c|}{ Valores de F (ninfas e ovos) } \\
\hline & & 3 daa & 6 daa & 17 daa & 49 daa & 12 daa & 22 daa & Ovos \\
\hline Produto $(\mathrm{P})$ & 2 & $268,6^{*}$ & $404,9^{*}$ & $317,3^{*}$ & $80,9^{*}$ & $35,0^{*}$ & $17,9^{*}$ & $7,9^{*}$ \\
\hline Tipo de Água (A) & 1 & $1,8^{\text {ns }}$ & $1,1^{\text {ns }}$ & $2,7^{\text {ns }}$ & $3,2^{\text {ns }}$ & $1,0^{\text {ns }}$ & $0,0^{\text {ns }}$ & $0,4^{\mathrm{ns}}$ \\
\hline Tempo preparo(T) & 1 & $1,2^{\text {ns }}$ & $1,1^{\text {ns }}$ & $0,0^{\text {ns }}$ & $2,6^{\mathrm{ns}}$ & $2,1^{\text {ns }}$ & $0,0^{\text {ns }}$ & 0,9 ns \\
\hline$P \times A$ & 2 & $0,7^{\text {ns }}$ & $0,4^{\text {ns }}$ & $2,7^{\text {ns }}$ & $3,2^{\text {ns }}$ & $0,5^{\text {ns }}$ & $0,0^{\text {ns }}$ & $1,6^{\mathrm{ns}}$ \\
\hline $\mathrm{P} \times \mathrm{T}$ & 2 & $1,2^{\mathrm{ns}}$ & $0,7^{\text {ns }}$ & $0,0^{\text {ns }}$ & $2,6^{\mathrm{ns}}$ & $1,0^{\mathrm{ns}}$ & $0,0^{\text {ns }}$ & $2,7^{\mathrm{ns}}$ \\
\hline$A \times T$ & 1 & $0,7^{\text {ns }}$ & $3,6^{\text {ns }}$ & $0,2^{\text {ns }}$ & $0,2^{\text {ns }}$ & $0,2^{\text {ns }}$ & $0,1^{\mathrm{ns}}$ & $0,8^{\mathrm{ns}}$ \\
\hline$P \times A \times T$ & 2 & $0,2^{\text {ns }}$ & $1,7^{\text {ns }}$ & $0,2^{\text {ns }}$ & $0,2^{\mathrm{ns}}$ & $1,7^{\mathrm{ns}}$ & $0,05^{\mathrm{ns}}$ & $0,2^{\mathrm{ns}}$ \\
\hline CV(\%) & & 30,31 & 28,0 & 38,9 & 77,0 & 60,3 & 161,2 & 203,8 \\
\hline
\end{tabular}

*Significativo pelo teste de Tukey $(\mathrm{p}<0,05)$. daa: dias após aplicaçăo.

Tabela 4. Efeito dos tratamentos acaricidas sobre o número médio de adultos vivos (M) e eficiência de controle (E\%) de Brevipalpus phoenicis sobre frutos de laranja doce. (Os tratamentos estão descritos nas tabelas 1 e 2)

\begin{tabular}{|c|c|c|c|c|c|c|c|c|c|}
\hline \multirow{3}{*}{ Trat. } & \multirow{3}{*}{$\begin{array}{c}\text { Prévia } \\
\text { M }\end{array}$} & \multicolumn{8}{|c|}{ Dias após aplicação (Daa) } \\
\hline & & \multicolumn{2}{|l|}{3} & \multicolumn{2}{|c|}{6} & \multicolumn{2}{|c|}{17} & \multicolumn{2}{|c|}{49} \\
\hline & & M & $\% \mathrm{E}^{(1)}$ & M & $\% \mathrm{E}$ & M & $\% \mathrm{E}$ & M & $\% \mathrm{E}$ \\
\hline T1 & $3,2 \pm 0,1 \mathrm{a}^{*}$ & $0,3 \pm 0,5 a b$ & 97 & $0,0 \pm 0,0 \mathrm{a}$ & 100 & $0,0 \pm 0,0 \mathrm{a}$ & 100 & $0,0 \pm 0,0 \mathrm{a}$ & 100 \\
\hline T2 & $3,1 \pm 0,1 \mathrm{a}$ & $0,0 \pm 0,0 \mathrm{a}$ & 100 & $0,0 \pm 0,0 \mathrm{a}$ & 100 & $0,0 \pm 0,0 \mathrm{a}$ & 100 & $0,0 \pm 0,0 \mathrm{a}$ & 100 \\
\hline T3 & $3,2 \pm 0,0 \mathrm{a}$ & $0,0 \pm 0,0 \mathrm{a}$ & 100 & $0,0 \pm 0,0 \mathrm{a}$ & 100 & $0,0 \pm 0,0 \mathrm{a}$ & 100 & $0,0 \pm 0,0 \mathrm{a}$ & 100 \\
\hline T4 & $3,1 \pm 0,2 \mathrm{a}$ & $0,3 \pm 0,5 \mathrm{ab}$ & 97 & $0,0 \pm 0,0 \mathrm{a}$ & 100 & $0,0 \pm 0,0 \mathrm{a}$ & 100 & $0,0 \pm 0,0 \mathrm{a}$ & 100 \\
\hline T5 & $3,1 \pm 0,1 \mathrm{a}$ & $3,1 \pm 0,1 \mathrm{~d}$ & 0 & $3,1 \pm 0,1 \mathrm{c}$ & 0 & $2,9 \pm 0,2 b$ & 0 & $1,8 \pm 0,7 b$ & 92 \\
\hline T6 & $3,1 \pm 0,1 \mathrm{a}$ & $3,1 \pm 0,1 \mathrm{~d}$ & 0 & $3,0 \pm 0,2 c$ & 0 & $2,8 \pm 0,2 b$ & 0 & $1,5 \pm 1,1 \mathrm{~b}$ & 92 \\
\hline T7 & $3,1 \pm 0,2 \mathrm{a}$ & $3,0 \pm 0,2 \mathrm{~d}$ & 10 & $2,9 \pm 0,3 c$ & 10 & $2,5 \pm 0,3 b$ & 16 & $0,7 \pm 0,8 b$ & 98 \\
\hline T8 & $3,1 \pm 0,1 \mathrm{a}$ & $3,0 \pm 0,2 \mathrm{~d}$ & 5 & $3,0 \pm 0,1 \mathrm{c}$ & 3 & $2,6 \pm 0,5 b$ & 10 & $0,4 \pm 0,9 \mathrm{~b}$ & 98 \\
\hline T9 & $3,1 \pm 0,1 \mathrm{a}$ & $1,5 \pm 1,1 \mathrm{c}$ & 67 & $1,4 \pm 0,9 \mathrm{~b}$ & 74 & $0,0 \pm 0,0 \mathrm{a}$ & 100 & $0,0 \pm 0,0 \mathrm{a}$ & 100 \\
\hline T10 & $3,2 \pm 0,2 \mathrm{a}$ & $1,0 \pm 0,8 \mathrm{abc}$ & 84 & $0,5 \pm 0,6 a b$ & 95 & $0,0 \pm 0,0 \mathrm{a}$ & 100 & $0,0 \pm 0,0 \mathrm{a}$ & 100 \\
\hline T11 & $3,1 \pm 0,1 \mathrm{a}$ & $1,5 \pm 0,3 c$ & 77 & $0,7 \pm 0,8 a b$ & 90 & $0,0 \pm 0,0 \mathrm{a}$ & 100 & $0,0 \pm 0,0 \mathrm{a}$ & 100 \\
\hline T12 & $3,2 \pm 0,0 \mathrm{a}$ & $1,3 \pm 0,5 b c$ & 81 & $1,0 \pm 0,8 a b$ & 84 & $0,0 \pm 0,0 \mathrm{a}$ & 100 & $0,0 \pm 0,0 \mathrm{a}$ & 100 \\
\hline T13 & $3,2 \pm 0,1 \mathrm{a}$ & $3,1 \pm 0,1 \mathrm{~d}$ & -- & $3,1 \pm 0,1 \mathrm{c}$ & -- & $2,8 \pm 0,3 b$ & -- & $6,1 \pm 3,5 b$ & -- \\
\hline T14 & $3,1 \pm 0,2 \mathrm{a}$ & $3,1 \pm 0,2 \mathrm{~d}$ & -- & $3,0 \pm 0,2 \mathrm{c}$ & -- & $2,8 \pm 0,4 b$ & -- & $6,1 \pm 1,8 \mathrm{~b}$ & -- \\
\hline CV (\%) & 4,2 & 25,8 & & 28,2 & & 17,5 & & 97,2 & \\
\hline DMS & 0,32 & 1,11 & & 1,11 & & 0,52 & & 2,90 & \\
\hline $\mathrm{F}$ & 0,36 & 33,9 & & 40,2 & & 188,1 & & 14,1 & \\
\hline $\mathrm{p}$ & 0,97 & $<0,0001$ & & $<0,0001$ & & $<0,0001$ & & $<0,0001$ & \\
\hline
\end{tabular}

*Médias transformadas em raiz de $\mathrm{x} \pm$ desvio-padrão. Médias seguidas pela mesma letra não diferem entre si pelo teste de Tukey (p<0,05). $\left({ }^{1}\right)$ Eficiência de controle calculada por Аввотт (1925). 
laboratório, aos 14 e 20 DAA do acaricida. Outra constatação de ANDRADE (1997) foi que nos acaricidas (óxido de fenbutatina, hexitiazoxi e dicofol) náo houve influência quando se utilizaram caldas com diferentes $\mathrm{pH}(3,6$ e 9) em relação a sua eficácia de controle sobre $B$. phoencis. Fato também constatado no presente trabalho com o produto hexitiazoxi para diferentes fontes d'água e $\mathrm{pH}$.

Os tratamentos com espirodiclofeno $(9,10,11$ e 12) proporcionaram mortalidade de $100 \%$ dos ácaros adultos aos $17 \mathrm{DAA}$, havendo bom controle para o ácaro da leprose (Tabela 4). Ressalta-se assim, que o tipo de água e o tempo de preparo não interferiram no desempenho de controle de nenhum acaricida estudado sobre fêmeas adultas do ácaro-da-leprose.

Aos 22 DAA, em todos os tratamentos houve 100\% de controle das ninfas de B. phoenicis, evidenciando que a eficácia dos acaricidas não foi afetada por uma possível hidrólise do ingrediente ativo em função do tempo de preparo e do $\mathrm{pH}$ da água utilizada na calda de pulverização (Tabela 5). Aos 49 DAA foi realizada uma avaliação quantificando o número de ovos presentes nos frutos. Nos frutos onde se aplicaram propargite (tratamentos 1 a 4) e espirodiclofeno (tratamentos 9 a 12), não foram observadas posturas, devido à ação adulticida desses produtos que eliminaram as fêmeas do ácaro, respectivamente, aos 6 e 17 DAA (Tabela 4). Ao contrário desses produtos, o aca- ricida hexitiazoxi não possui efeito de choque nos ácaros adultos, permanecendo nas arenas fêmeas dos ácaros que realizavam a postura normalmente.

Relativo à oviposição, não foram observadas diferenças entre os tratamentos com o acaricida hexitiazoxi aos 49 DAA quanto ao número de ovos, o que evidenciou novamente a não-interferência do tipo de água e tempo de preparo da calda desse acaricida (Tabela 5).

Ao se avaliar o comportamento do potencial hidrogeniônico das caldas acaricidas com as diferentes fontes de água, ao longo de 24 horas após seu preparo, observou-se que as variaçóes do $\mathrm{pH}$ foram pequenas em relaçâo aos valores obtidos somente com água; esse valor foi sempre menor que 2 décimos, quando em uso a água do sistema público de abastecimento (tratada) (Figura 2), e quase sempre menor que 1 décimo de variação quando os acaricidas foram misturados com água "dura" (Figura 3). Assim, os acaricidas nas dosagens avaliadas não alteraram os valores do $\mathrm{pH}$ da água, independentemente do tempo transcorrido após a mistura, contrariando KissmanN (1998), quando afirma que o acréscimo de produtos fitossanitários à água tende a alterar os valores de $\mathrm{pH}$ da calda. Com base nessas informaçōes, é possível afirmar que as águas exerceram um forte poder tampáo (capacidade de manter o pH em uma determinada faixa) após a adição dos agrotóxicos.

Tabela 5. Efeito dos tratamentos acaricidas sobre o número médio de ninfas vivas $(\mathrm{N})$ ou de ovos $(\mathrm{O})$ e eficiência de controle (E\%) de Brevipalpus phoenicis sobre frutos de laranja doce. (Os tratamentos estão descritos nas tabelas 1 e 2)

\begin{tabular}{|c|c|c|c|c|c|c|c|c|}
\hline \multirow{3}{*}{ Trat. } & \multicolumn{8}{|c|}{ Dias após aplicação } \\
\hline & \multirow{2}{*}{$\begin{array}{c}\text { Prévia (1) } \\
\text { O }\end{array}$} & \multicolumn{2}{|c|}{12} & \multicolumn{2}{|c|}{22} & \multicolumn{2}{|c|}{49} & \multirow{2}{*}{$\begin{array}{c}\text { Ovos } \\
0\end{array}$} \\
\hline & & $\mathbf{N}$ & $\% \mathrm{E}^{(3)}$ & $\mathbf{N}$ & $\% \mathrm{E}$ & $\mathbf{N}$ & $\% \mathrm{E}$ & \\
\hline T1 & $5,0 \pm 1,6 \mathrm{a}^{*}$ & $0,8 \pm 0,9 a b$ & 94 & $0,0 \pm 0,0 a$ & 100 & $0,0 \pm 0,0 a$ & 100 & $0,0 \pm 0,0 a$ \\
\hline T2 & $4,8 \pm 1,8 \mathrm{a}$ & $0,3 \pm 0,5 \mathrm{a}$ & 97 & $0,0 \pm 0,0 a$ & 100 & $0,0 \pm 0,0 a$ & 100 & $0,0 \pm 0,0 a$ \\
\hline T3 & $5,5 \pm 1,4 \mathrm{a}$ & $1,0 \pm 0,8 \mathrm{abc}$ & 91 & $0,0 \pm 0,0 a$ & 100 & $0,0 \pm 0,0 \mathrm{a}$ & 100 & $0,0 \pm 0,0 a$ \\
\hline T4 & $5,1 \pm 1,2 \mathrm{a}$ & $1,5 \pm 1,1 \mathrm{abc}$ & 83 & $0,0 \pm 0,0 a$ & 100 & $0,0 \pm 0,0 a$ & 100 & $0,0 \pm 0,0 a$ \\
\hline T5 & $5,7 \pm 1,3 a$ & $2,6 \pm 0,7 \mathrm{bcd}$ & 67 & $0,0 \pm 0,0 a$ & 100 & $0,0 \pm 0,0 a$ & 100 & $8,3 \pm 5,7$ bc \\
\hline T6 & $5,0 \pm 1,4 \mathrm{a}$ & $3,0 \pm 1,0 \mathrm{~cd}$ & 56 & $0,3 \pm 0,5 \mathrm{a}$ & 100 & $0,0 \pm 0,0 a$ & 100 & $7,2 \pm 2,4$ bc \\
\hline T7 & $6,1 \pm 0,8 \mathrm{a}$ & $3,1 \pm 0,8 \mathrm{~cd}$ & 54 & $0,0 \pm 0,0 a$ & 100 & $0,0 \pm 0,0 a$ & 100 & $6,1 \pm 2,8 \mathrm{abc}$ \\
\hline T8 & $5,9 \pm 0,5 \mathrm{a}$ & $2,8 \pm 0,7 \mathrm{bcd}$ & 59 & $0,0 \pm 0,0 a$ & 100 & $0,0 \pm 0,0 a$ & 100 & $4,4 \pm 1,8 a b$ \\
\hline T9 & $5,8 \pm 0,8 \mathrm{a}$ & $0,8 \pm 0,9 a b$ & 86 & $0,0 \pm 0,0 a$ & 100 & $0,0 \pm 0,0 \mathrm{a}$ & 100 & $0,0 \pm 0,0 a$ \\
\hline T10 & $5,8 \pm 0,5 \mathrm{a}$ & $1,9 \pm 0,9 a b c$ & 73 & $0,0 \pm 0,0 a$ & 100 & $0,0 \pm 0,0 a$ & 100 & $0,0 \pm 0,0 a$ \\
\hline T11 & $6,5 \pm 0,7 \mathrm{a}$ & $0,9 \pm 1,0 \mathrm{ab}$ & 83 & $0,0 \pm 0,0 a$ & 100 & $0,0 \pm 0,0 a$ & 100 & $0,0 \pm 0,0 a$ \\
\hline T12 & $5,9 \pm 1,2 \mathrm{a}$ & $1,9 \pm 0,5 \mathrm{abc}$ & 73 & $0,0 \pm 0,0 a$ & 100 & $0,0 \pm 0,0 a$ & 100 & $0,0 \pm 0,0 a$ \\
\hline T13 & $5,9 \pm 1,0 \mathrm{a}$ & $4,7 \pm 1,0 \mathrm{~d}$ & -- & $6,6 \pm 2,2 b$ & -- & $5,6 \pm 3,7 b$ & & $10,0 \pm 6,0 \mathrm{bc}$ \\
\hline T14 & $5,9 \pm 0,3 \mathrm{a}$ & $4,6 \pm 0,6 d$ & -- & $7,8 \pm 0,7 \mathrm{~b}$ & -- & $5,3 \pm 0,9 b$ & & $11,4 \pm 2,6 \mathrm{c}$ \\
\hline CV (\%) & 19,9 & 40,0 & & 60,1 & & 130,3 & & 75,4 \\
\hline DMS & 2,8 & 2,1 & & 1,6 & & 2,5 & & 6,4 \\
\hline $\mathrm{F}$ & 0,72 & 11,3 & & 69,5 & & 15,2 & & 11,6 \\
\hline$P$ & 0,73 & $<0,0001$ & & $<0,0001$ & & $<0,0001$ & & $<0,0001$ \\
\hline
\end{tabular}

*Médias transformadas em raiz de $\mathrm{x} \pm$ desvio-padrăo. Médias seguidas pela mesma letra năo diferem entre si pelo teste de Tukey (p<0,05). $\left({ }^{1}\right)$ Número total de ovos 4 dias após infestação do ácaro. $\left({ }^{2}\right)$ Número total de ovos 49 dias após infestação. ${ }^{3}$ ) Eficiência de controle calculada por Aввотт (1925). 
Os valores de $\mathrm{pH}$ para todos os tratamentos utilizados manteve-se sempre acima de 7,0, faixa considerada alcalina, especialmente para os tratamentos em água "dura", onde o $\mathrm{pH}$ se manteve entre valores de 9,2 e 9,4 até 24 horas após a mistura dos acaricidas (Figura 3).

Segundo Kissmann (1997) e ConCeição (2003), os produtos fitossanitários têm maior eficiência quando as caldas são ácidas, com pH entre 4,0 e 7,0, sendo necessária a correção do $\mathrm{pH}$ em alguns casos. No entanto, os resultados de controle dos ácaros nesse experimento ( $\mathrm{Ta}$ belas 3 e 4) não confirmam as informaçôes relatadas por esses autores, visto que os acaricidas têm boa eficácia de controle mesmo com valores de $\mathrm{pH}$ alcalinos nas caldas. É oportuno salientar que a maior uniformidade da cobertura de pulverizaçáo sobre os frutos, em laboratório, comparada àquelas realizadas em campo pode ter compensado uma suposta alteração na eficiência química das moléculas, porém não suficiente ao ponto de se detectar diferenças entre os tratamentos em teste.

Diferentemente do ocorrido no presente trabalho, Ghillebaert et al. (1996), estudando os efeitos da concentração de cálcio e valores diferentes de $\mathrm{pH}$ em solução com o inseticida deltametrina, observou que o aumento na concentração de $\mathrm{Ca}^{+2}$ e $\mathrm{pH}$ alcalino $(\mathrm{pH}=9,0)$ propiciou decréscimo da toxicidade do inseticida deltametrina em larvas de carpa comum, Cyprinus carpio L.(Cipriniforme: cyprinidae).

Mesmo que tenha ocorrido hidrólise alcalina parcial dos três acaricidas estudados, fato que segundo Reeves (1983) pode ocorrer em águas com altos níveis de $\mathrm{pH}$ e gerar ineficiência do produto, não foi suficiente para diminuir a toxicidade dos acaricidas estudados neste trabalho. Al-Mughrabi et al. (1992), estudando efeito de água dura e $\mathrm{pH}$ elevado em solução com o inseticida cipermetrina, não observaram efeitos relevantes de hidrólise dessa molécula.

Pulverizaçóes com acaricidas em soluções com água dura e $\mathrm{pH}$ elevado, no campo, podem proporcionar resultados contraditórios aos obtidos neste trabalho, uma vez que existem diversos fatores ambientais que podem contribuir para ineficiência de acaricidas. Dessa forma, novas pesquisas em campo referente ao tipo de água e o tempo de preparo das soluçôes de agrotóxicos a serem utilizadas nas pulverizações devem ser realizadas para melhor entendimento desses fatores.

\section{CONCLUSÃO}

Pelos resultados relatados neste trabalho conclui-se que a dureza da água, o potencial hidrogênionico $(\mathrm{pH})$ das caldas acaricidas e o tempo de preparo das caldas antes do uso não interferiram na eficácia de controle do ácaro da leprose $B$. phoenicis pelos acaricidas propargite, hexitiazoxi e espirodiclofeno.

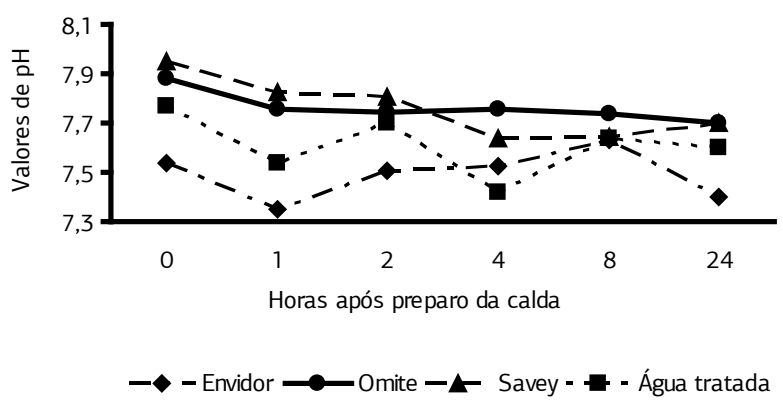

Figura 2. Valores médios do $\mathrm{pH}$ das diferentes caldas acaricidas em água do sistema público de abastecimento ( $\mathrm{pH} 7,77)$ durante 24 horas.

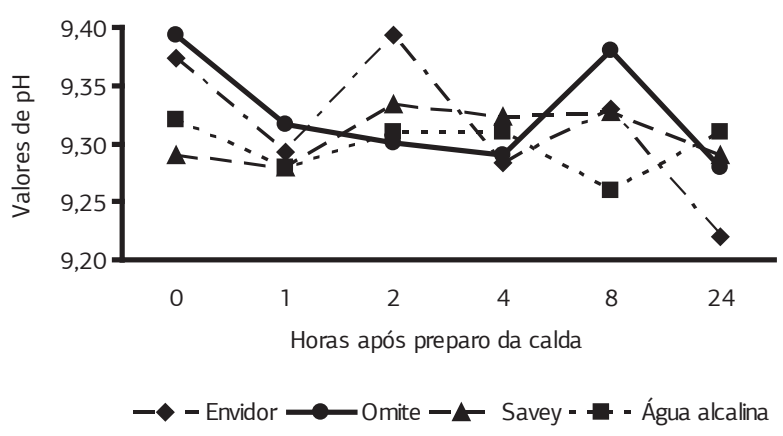

Figura 3. Valores médios do $\mathrm{pH}$ das diferentes caldas acaricidas com o uso de água alcalina ("dura") ( $\mathrm{pH}$ inicial igual 9,32) durante 24 horas.

\section{AGRADECIMENTOS}

Ao funcionário do Departamento de Produção Vegetal Defesa Fitossanitária, Domingos Paulossi, pela ajuda no desenvolvimento deste trabalho, e ao Conselho Nacional de Desenvolvimento Científico e Tecnológico - CNPq, pela concessão de bolsa ao primeiro autor.

\section{REFERÊNCIAS}

ALBUQUERQUE, F.A.; OLIVEIRA, C.A.L.; BARRETO, M. Estudos da relação entre as incidências de verrugose da laranjadoce e leprose dos citros em frutos de laranja pêra, Científica, v.25, p.393-402, 1997.

ABBOTT, W.S. A method of computing the effectiveness of an insecticide. Journal of Economic Entomology, v.18, p. 265-267, 1925.

AL-MUGHRABI, K.I.; NAZER, I.K. Chemistry of King Canal water in the Jordan Valley. II. Effect of water $\mathrm{pH}$ on the stability of Dimetoato. Arabian Gulf Science, v.2, p.13-22, 1991.

AL-MUGHRABI, K.I.; NAZER, I.K.; AL-SHURAIQI, Y.T. Effect of water from the King Abdallah Canal in Jordan on the stability of cipermethrin. Crop Protection, v.11, p.341-344, 1992. 
ANDRADE, T.L.C. Ação acaricida do hexythiazox, dicofol e do óxido de fenbutatin, em três níveis de $\mathrm{pH}$ da calda no controle de Brevipalpus phoenicis Geijskes, em condiçôes de laboratório. 1997. 71f. Dissertação (Mestrado em Agronomia - Entomologia Agrícola) Universidade Estadual Paulista, Faculdade de Ciências Agrárias e Veterinária, Jaboticabal.

ANDREI, E. Compêndio de defensivos agrícolas. 7.ed. São Paulo: Andrei, 2005. 1141p.

CHIAVEGATO, L.G.; MISCHAN, M.M.; SILVA, M.A. Prejuízos e transmissibilidade de sintomas de leprose pelo ácaro Brevipalpus phoenicis (Geijskes, 1939) (Acari, Tenuipalpidae) em citros. Científica, v.10, p.265-271, 1982.

CHIAVEGATO, L.G.; MISCHAN, M.M. Comportamento do ácaro Brevipalpus phoencis (Geijskes, 1939) (Acari: Tenuipalpidae) em frutos de diferentes variedades cítricas. Científica, v.15, p.17-22, 1987.

CONCEIÇÃO, M.Z. Defesa vegetal: legislação, normas e produtos fitossanitários. In: ZAMBOLIN, L.; CONCEIÇĀO, M.Z.; SANTIAGO, T. (Ed.). O que os Engenheiros Agrônomos devem saber para orientar o uso de produtos fitossanitários. 2.ed. Viçosa: UFV, 2003. p.53-57.

GHILlEBAERT, F.; PRODORUTTI, D.; CHAILlOU, C.; ROUBAUD, P. Deltamethrin Lethal Multifactorial Activity Carp Larva Related to $\mathrm{pH}$, Calcium, and Humic Acid Concentrations. Ecotoxicology and Environmental Safety, v.35, p.24-37, 1996.

KISSMANN, K.G. Adjuvantes para caldas de produtos fitossanitários. In: CONGRESSSO BRASILEIRO DA CIÊNCIA DAS PLANTAS DANINHAS, 21., 1997, Caxambu, MG. Palestras... Caxambu, MG: Sociedade Brasileira da Ciência das Plantas Daninhas, 1997. p.61-77.

KISSMANN, K.G. Adjuvantes para caldas de produtos fitossanitários. In:Tecnologia e segurança na aplicação de agrotóxicos: novas tecnologias, 1998. Santa Maria, RS: Departamento de Defesa Fitossanitária Sociedade de Agronomia de Santa Maria, 1998. p.39-51.

KITAJIMA, E.W.; MULLER, G.W.; COSTA, A.S.; YUKI, V.A. Short, rod-like particles associated with citrus leprosies. Virology, v. 50, p. 254-258, 1972.
MUSUMECI, M.R.; ROSSETTI, V. Transmissão dos sintomas da leprose dos citros pelo ácaro Brevipalpus phoenicis. Ciência e Cultura, v.15, 1963. 228p.

NAKANO, O.; SILVEIRA NETO, O.; ZUCCHI, R.A. Entomologia econômica. São Paulo: Escola Superior de Agricultura "Luiz de Queiroz", 1981. 314p.

OLIVEIRA, C.A.L.; MATUO, T.; SANTOS JR., J.E.; TOLEDO, M.C. 1997. Efeito de Espalhante-Adesivo na Eficiência dos Acaricidas Propargite e Cyhexatin no Controle do Brevipalpus phoenicis (Geijskes) (Acari: Tenuipalpidae) em Citros. Anais da Sociedade Entomológica, v.26, p.487-493, 1997.

OLIVEIRA, C.P.; OLIVEIRA, C.A.L; MELO, W.J. Efeito da adição de óleos mineral e vegetal a acaricidas no controle do ácaro-da-leprose dos citros Brevipalpus phoenicis (Geijskes) (acari: Tenuipalpidae). Revista Brasileira de Fruticultura, v.25, p.224-226, 2003

RAMOS, H. H.; YANAI, K.; CORREAA, I. M.; BASSANEZI, R. B.; GARCIA, L. C. Efeito do volume de calda aplicado com turbopulverizador sobre o controle do ácaro da leprose em citros. In: Simpósio internacional de tecnologia de aplicação de agrotóxicos, 3., 2004, Botucatu, SP. Anais... Botucatu, SP: Fundação de Estudos e Pesquisas Agropecuárias e Florestais, 2004. p.140-143. CDROM.

REEVES, B. The effect of water $\mathrm{pH}$ on pesticides. Oregon Horticultural Society, v.74, p.138-142, 1983.

RODRIGUES, J.C.V., CHILDERS, C.C., KITAJIMA, E.W., MACHADO, M.A., NOGUEIRA, N.L. Uma estratégia para o controle da leprose dos citros. Laranja, v.22, p.411-423, 2001.

RODRIGUES, J.C.V;; OLIVEIRA, C.A.L. Ácaros fitófagos dos citros. In: JUNIOR, D.M.; NEGRI, J.D.; PIO, R.M.; JUNIOR, J.P. Citros. Campinas: Instituto Agronômico e Fundag, 2005. p.691-718.

SILVA, F.A.S.E.; AZEVEDO, C.A.V. A New Version of The Assistat-Statistical Assistance Software. In: World congress on computers in agriculture, 4, Orlando-FL-USA: Anais... Orlando: American Society of Agricultural Engineers, 2006. p.393-396. 